\title{
Changes in Responsiveness to Mu and Kappa Opiates following a Series of Convulsions
}

\author{
Alfred Mansour and Elliot S. VALENSTein ${ }^{1}$ \\ Department of Psychology and Neuroscience Laboratory, 1103 E. Huron Street, \\ University of Michigan, Ann Arbor, Michigan 48104-1687
}

Received May 10, 1985

\begin{abstract}
After a series of seven electroconvulsive shocks, mice (C57BL/6J) showed a marked change in their response to opiates. Although very large doses of mu agonists induce convulsions in normal control mice, our evidence indicated that this was accomplished through nonopiate mechanisms: they could not be blocked by naltrexone and the pattern of drug potencies (codeine $>$ morphine $>$ levorphanol) was not consistent with an opiate response. In contrast, after electroconvulsive shock small doses of mu agonists induced convulsions that could be blocked by naltrexone and the pattern of drug potency (levorphanol $>$ morphine $>$ codeine) was consistent with an opiate mechanism. Kappa drugs, on the other hand, produced convulsions in both control and ECS animals, although there was an enhanced responsiveness in the latter. Furthermore, the convulsions produced by kappa drugs were blocked by naltrexone and showed stereoselectivity in both control and ECS animals. The changes in responsiveness to mu and kappa opiates cannot be explained on the basis of a general increase in seizure susceptibility, as sensitivity to the nonopiate convulsant, strychnine, was not enhanced after electroconvulsive shock. The results point to a qualitative change in response to mu agonists after electroconvulsive shock, but only a change in sensitivity to kappa agonists. 1985 Academic Press, Inc.
\end{abstract}

\section{INTRODUCTION}

Previous research in our laboratory demonstrated that animals receiving a series of convulsions by amygdala stimulation, metrazol, or electroconvulsive shock (ECS) showed generalized nonlethal clonic convulsions to doses of morphine that produced no convulsive effects in their respective controls $(8,9)$. The changes in morphine responsiveness were enduring and could be detected to 3 months after an animal's last amygdala-kindled convulsion. Further, the morphine-induced convulsions observed in animals

Abbreviations: ECS-electroconvulsive shock, EKC-ethylketazocine.

${ }^{1}$ The authors acknowledge the support of National Institutes of Health grant 5 R01NS19607. 
with a history of convulsions appear to be a specific action of the drug, as they could be blocked by small doses of opiate antagonists.

While pursuing these effects we observed that morphine could induce convulsions in normal animals, but it required lethal doses and the druginduced convulsions could not be blocked by pretreatment with even large doses $(30$ to $100 \mathrm{mg} / \mathrm{kg}$ ) of naltrexone. It was unclear, then, whether the changes induced by a history of convulsions represented a qualitatively different response to morphine, or only a change in sensitivity. We, therefore, systematically examined the pharmacologic properties of the enhanced opiate response that follows convulsions, hypothesizing that if the changes were qualitative, then animals with a history of convulsions should respond differently to a series of opiate drugs.

Specifically, we compared the responses of ECS and control animals to levorphanol, codeine, and morphine and examined whether or not the drug effects could be blocked by naltrexone pretreatment. Particular attention was paid to the pattern of drug potencies of these mu agonists in inducing convulsions to determine if the response was consistent with other established opiate effects. A change in sensitivity would be inferred if mu opiates produced convulsions through an opiate mechanism in both ECS and control animals, whereas a qualitative change would be inferred if mu opiates produced convulsions by an opiate mechanism only after a history of ECS convulsions.

In addition, to determine if ECS also produces functional changes in kappa opiate receptors, we examined whether ECS animals were more responsive to ethylketazocine (EKC) and UM 1071, two kappa opiate agonists $(3,7,17)$. Because we found EKC and UM 1071 to be potent convulsants, we examined whether or not the convulsions showed stereoselectivity and could be blocked by naltrexone pretreatment.

As there was evidence in the literature to indicate that animals with a history of convulsions were more sensitive to convulsant drugs [e.g., (13)], we examined whether or not the enhanced responsiveness to opiates observed in kindled and ECS animals was due to a general increase in seizure proneness by determining if ECS animals were more sensitive to metrazol and strychine, two nonopiate convulsants.

Lastly, the convulsion history, including the number of convulsions, the elapsed time from the last convulsion, and whether or not convulsions were essential for inducing the observed effect, was also explored.

\section{METHODS}

General Methods. All animals used in the following experiments were adult C57BL/6J mice either bought from Jackson Laboratories, Bar Harbor, Maine or bred in our laboratory from Jackson stock. The animals were 
maintained on a 12-h light:12-h dark cycle with food and water available ad libitum. All drug data points were based on a minimum of six animals and all testing was conducted during the first $6 \mathrm{~h}$ of the dark phase.

The animals were injected i.p. and the range of doses was based on the results of pilot experiments. The animals were randomly assigned to a drug condition and tested only oncc. The percentage of animals showing a generalized convulsion, including clonic limb movements and falling, was recorded for each drug condition and was used as the dependent variable in each of the experiments.

Unless otherwise indicated, the animals received seven daily electroconvulsive shocks and were tested 3 days after their last convulsion. The ECS procedure consisted of passing electricity to the cornea $(6.5 \mathrm{~mA}, 0.5 \mathrm{~s})$ through two saline-soaked gauze pads attached to two wooden dowels. The ECS and control animals were handled identically except that the latter were not shocked.

\section{Experiment I. Changes in Responsiveness to Mu Agonists That followed Electroconvulsive Shock}

Levorphanol, Morphine, and Codeine Dose-Response Curves in ECS and Control Animals. Eight groups ( $N=6$ or 7$)$ of ECS animals were tested with different doses of levorphanol $(10$ or $30 \mathrm{mg} / \mathrm{kg})$, morphine $(25,60$, or $100 \mathrm{mg} / \mathrm{kg}$ ), or codeine $(60,100$, or $170 \mathrm{mg} / \mathrm{kg})$. For comparison, nine groups $(N=6$ to 8$)$ of handled control mice were similarly tested with levorphanol $(30,100$, or $300 \mathrm{mg} / \mathrm{kg})$, morphine $(100,300$, or $600 \mathrm{mg} / \mathrm{kg})$, or codeine $(100,170$, or $300 \mathrm{mg} / \mathrm{kg})$. These three drugs were chosen because they are relatively specific mu agonists and differ widely in their potencies (2). The percentage of ECS and control mice that convulsed after the injection of levorphanol or morphine was recorded during a 90-min observation period. The ECS and control animals that received codeine were observed for only 30 min postinjection because of its short duration of action.

As levorphanol failed to elicit convulsions in control mice, an additional group $(N=9)$ of animals was implanted with a bipolar electrode in the frontal cortex. The animals were handled for 7 days and tested with 300 $\mathrm{mg} / \mathrm{kg}$ levorphanol 3 days later to determine if levorphanol produced any electrographic evidence of seizures in normal animals.

Naltrexone Blockade of Levorphanol-, Morphine-, and Codeine-Induced Convulsions in ECS and Control Animals. Ten groups $(N=6$ to 13) of ECS animals were pretreated with either saline or one of several doses of naltrexone $(0.1,0.3,1.0$, or $3.0 \mathrm{mg} / \mathrm{kg}) 5 \mathrm{~min}$ prior to receiving either levorphanol $(30 \mathrm{mg} / \mathrm{kg})$, morphine $(100 \mathrm{mg} / \mathrm{kg})$, or codeine $(100 \mathrm{mg} / \mathrm{kg})$. We chose these doses of levorphanol, morphine, and codeine because they 
produced no significant difference in the percentage of ECS animals convulsing ( $\chi=3.0, \mathrm{df}=2$, n.s.). For comparison, nine groups $(N=6$ to 7) of control mice were pretreated with either saline or naltrexone (3.0, $10.0,30.0$, or $100 \mathrm{mg} / \mathrm{kg}) 5 \mathrm{~min}$ prior to either morphine $(600 \mathrm{mg} / \mathrm{kg})$ or codeine $(300 \mathrm{mg} / \mathrm{kg})$. Larger doses of morphine and codeine were used in control animals in order to produce convulsions in a percentage of animals equivalent to that seen in ECS animals. We did not attempt to block the effects of levorphanol with naltrexone in control animals, for it failed to induce convulsions even at lethal doses.

\section{Experiment II. Changes in Sensitivity to Kappa Agonists after Electroconvulsive Shock}

Ethylketazocine and (-)UM 1071 Dose-Response Curves in ECS and Control Animals. Six groups ( $N=6$ to 8) of ECS animals were tested with one of several doses of EKC $(1.0,1.7$, or $3.0 \mathrm{mg} / \mathrm{kg})$ or $(-) \mathrm{UM} 1071$ $(1.0,1.7$, or $3.0 \mathrm{mg} / \mathrm{kg})$ to determine a dose-response curve for each drug. Six groups $(N=6$ to 8$)$ of controls were similarly tested with either EKC $(3.0,6.0$, or $10.0 \mathrm{mg} / \mathrm{kg})$ or $(-) \mathrm{UM} 1071(3.0,6.0$, or $10.0 \mathrm{mg} / \mathrm{kg})$. The percentage of ECS and control mice that convulsed was recorded during a 30-min observation period for each drug and dose condition.

Naltrexone Blockade of EKC- and (-)UM 1071-Induced Convulsions in ECS and Control Animals. Eight groups $(N=7)$ of ECS animals were pretreated with either saline or one of several doses of naltrexone $(0.1,0.3$, 1.0 , or $3.0 \mathrm{mg} / \mathrm{kg}) 5 \mathrm{~min}$ prior to either $3.0 \mathrm{mg} / \mathrm{kg} \mathrm{EKC} \mathrm{or} 3.0 \mathrm{mg} / \mathrm{kg}$ $(-)$ UM 1071. Seven groups $(N=6$ or 7$)$ of handled controls were similarly pretreated with either saline or naltrexone $(0.1,0.3,1.0$, or $3.0 \mathrm{mg} / \mathrm{kg}) 5$ min prior to either $10 \mathrm{mg} / \mathrm{kg}$ EKC or $10 \mathrm{mg} / \mathrm{kg}(-) \mathrm{UM} 1071$. These doses of EKC and (-)UM 1071 were used because they produced convulsions in an equivalent percentage of ECS and control animals.

Stereospecificity. We examined the stereospecificity of the convulsions induced by kappa agonists by comparing the effects of $(+) \mathrm{UM} 1071$ with its stereoisomer in ECS and control animals. Three groups $(N=8)$ of ECS animals were treated with either 10,100 , or $170 \mathrm{mg} / \mathrm{kg}(+) \mathrm{UM} 1071$. For comparison, three groups $(N=6)$ of control animals were similarly treated with 100,170 , or $300 \mathrm{mg} / \mathrm{kg}(+) \mathrm{UM} 1071$. The percentage of ECS and control mice that convulsed was recorded during a 30-min observation period for each dose of drug.

\section{Experiment III. Changes in Response to Nonopiate Convulsants That follow Electroconvulsive Shock}

We examined the specificity of the changes in opiate responsiveness by testing whether ECS animals were more sensitive to metrazol and strychnine, 
two nonopiate convulsants. Three groups ( $N=6$ to 8$)$ of ECS mice were tested with 40,45 , or $50 \mathrm{mg} / \mathrm{kg}$ metrazol 3 days after their last convulsion. Four groups $(N=6$ to 8$)$ of control animals were similarly handled and tested with $40,45,50$, or $60 \mathrm{mg} / \mathrm{kg}$ metrazol. An additional four groups $(N=6$ to 10$)$ of ECS and control animals were tested with strychnine $(1.0,1.5,1.8$, or $2.0 \mathrm{mg} / \mathrm{kg})$. The percentage of ECS and control mice that convulsed to metrazol or strychnine was recorded during a 30 -min observation period.

\section{Experiment IV. Variables Influencing the Change in Responsiveness to Opiates That follow Electroconvulsive Shock}

Number of Convulsions. Three groups $(N=7)$ of ECS animals received 23 electroconvulsive shocks and were tested 3 days later with either 0.3 , 1.0 , or $1.7 \mathrm{mg} / \mathrm{kg}$ EKC. Three groups $(N=6)$ of control animals were similarly handled for 23 days and tested 3 days later with $\operatorname{EKC~}(3,10$, or $17 \mathrm{mg} / \mathrm{kg}$ ). These data were compared with those reported in experiment II in which mice were tested after 7 days of ECS or handling.

Time from Last Convulsion. A group $(N=8)$ of ECS mice was given seven convulsions and tested with morphine $(100 \mathrm{mg} / \mathrm{kg}) 30$ days after their last treatment. These data were compared with those reported in experiment $\mathbf{I}$ in which animals were tested 3 days after their last convulsion.

The Necessity of Convulsions in Producing a Change in Opiate Responsiveness. Two groups of naive mice $(N=6$ or 7$)$ received a subconvulsive dose of EKC $(1 \mathrm{mg} / \mathrm{kg})$ for 20 consecutive days and were tested 3 days later with either 100 or $300 \mathrm{mg} / \mathrm{kg}$ morphine. This dose of EKC, although moderately large, failed to elicit a convulsion throughout the treatment paradigm. These animals were compared with two groups $(N=7$ or 8$)$ of mice that received seven convulsions induced by EKC $(10 \mathrm{mg} / \mathrm{kg})$ and were tested 3 days later with morphine ( 30 or $100 \mathrm{mg} / \mathrm{kg}$ ). The $10 \mathrm{mg} / \mathrm{kg}$ dose of EKC induced daily convulsions in the majority of animals.

\section{RESULTS}

Experiment I. The dose-response curves of levorphanol, morphine, and codeine for ECS and control animals are presented in Fig. 1. As this figure shows, animals became more responsive to all three mu opiates following ECS. Of particular importance, the pattern of drug effects differed in the ECS and control animals. After ECS, levorphanol $(30 \mathrm{mg} / \mathrm{kg})$ was found to be more effective than morphine $(25 \mathrm{mg} / \mathrm{kg})\left(\chi^{2}=6.2, P<0.05\right)$ and morphine $(60 \mathrm{mg} / \mathrm{kg})$ was more effective than codeine $(60 \mathrm{mg} / \mathrm{kg})$ $\left(\chi^{2}=3.82, P<0.05\right)$ in inducing convulsions. In control animals, in contrast, codeine $(300 \mathrm{mg} / \mathrm{kg})$ was more effective than morphine $(300 \mathrm{mg} /$ kg) $\left(\chi^{2}=7.14, P<0.01\right)$ in inducing convulsions, and levorphanol failed 


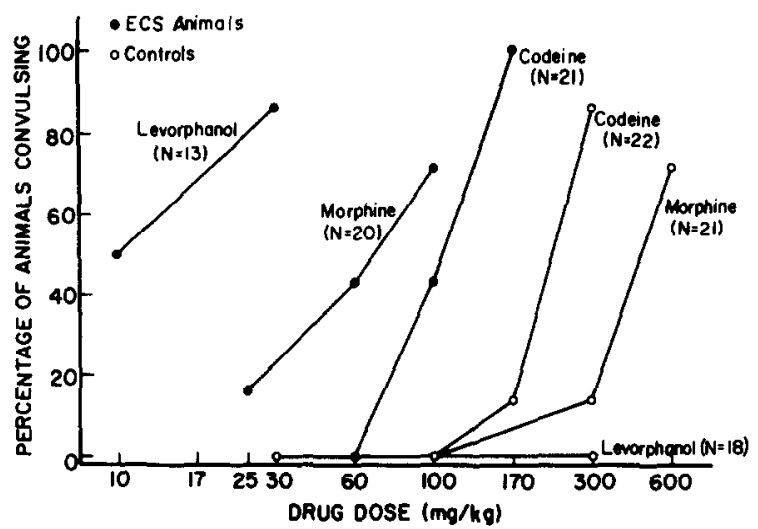

FIG. 1. Percentage of mice that received electroconvulsive shock (ECS) and control mice convulsing to morphine, levorphanol, or codeine 3 days after seven ECSs. All control animals were handled the same as ECS animals, but were not shocked. All data points are based on six or more animals; total number of animals per drug is in parentheses.

to elicit convulsions even at lethal doses. At large doses of levorphanol (300 $\mathrm{mg} / \mathrm{kg}$ ), control animals showed only a brief period of behavioral spasticity that was accompanied by respiratory depression and death. These behavioral effects were not, however, associated with any seizure activity in the frontal cortex.

The convulsions induced by the mu opiates differed in the ECS and control mice. In ECS animals, morphine and levorphanol induced clonic convulsions that were not lethal. In contrast, in control animals levorphanol did not produce any convulsions and the convulsions produced by morphine were almost always lethal (12 of 13). In the case of codeine, however, doses that produced convulsions were always lethal in both the control and ECS animals.

The drug-induced convulsions observed in the ECS and control animals also differed in their response to naltrexone pretreatment (Fig. 2). In ECS animals, naltrexone $(3 \mathrm{mg} / \mathrm{kg})$ effectively blocked the convulsions induced by morphine $\left(\chi^{2}=5.12, P<0.05\right)$, codeine $\left(\chi^{2}=5.6, P<0.05\right)$ and levorphanol $\left(\chi^{2}=6.23, P<0.05\right)$. In control animals, naltrexone failed to block the convulsions induced by morphine or codeine; however, large doses of naltrexone (30 and $100 \mathrm{mg} / \mathrm{kg}$ ) prevented morphine from killing control animals during the observation period, an effect not seen with saline pretreatment.

Experiment $I I$. In addition to showing an altered response to mu agonists, ECS animals showed a heightened sensitivity to the convulsant effects of kappa agonists. As seen in Fig. 3, ECS animals showed a half log unit shift to the left to both EKC $\left(\chi^{2}=8.04, P=0.01\right.$, at $\left.3 \mathrm{mg} / \mathrm{kg}\right)$ and $(-) \mathrm{UM}$ 

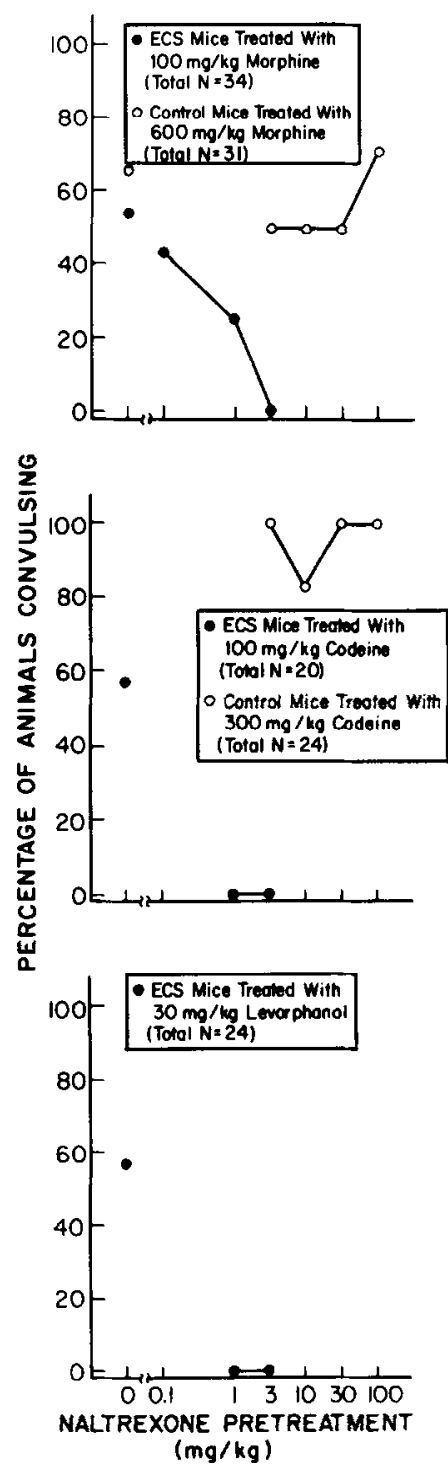

FIG. 2. Percentage of mice convulsing to morphine, codeine, or levorphanol administered 5 min after saline or different doses of naltrexone. All data points are based on six or more animals. All control animals were handled the same as ECS animals, but were not shocked.

$1071\left(\chi^{2}=6.56, P<0.05\right.$, at $3 \mathrm{mg} / \mathrm{kg}$ ). In contrast to the convulsions observed with mu opiates, EKC- and (-)UM 1071-induced convulsions were not lethal in the control animals and naltrexone pretreatment blocked 

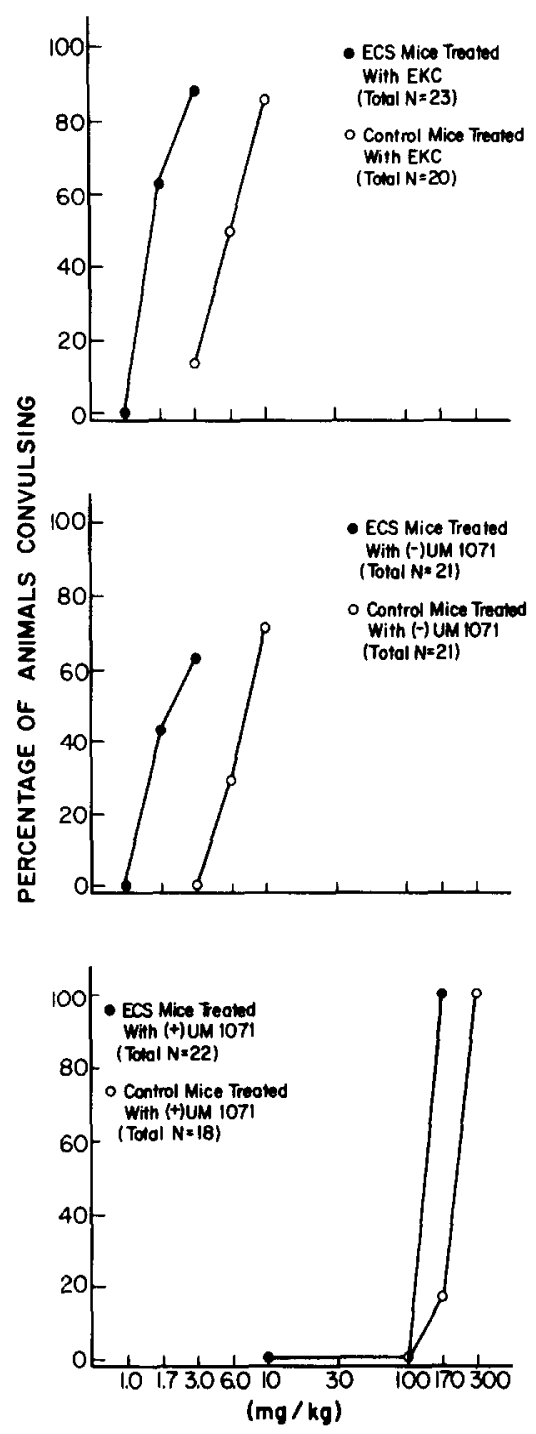

Fig. 3. Percentage of ECS and control mice convulsing to EKC, (-)UM 1071, or (+)UM 10713 days after seven ECSs. All control animals were handled the same as ECS animals, but were not shocked. All data points are based on six or more animals.

the EKC- and (-)UM 1071-induced convulsions in both the control as well as the ECS animals (Fig. 4).

The convulsions induced by the kappa agonists were stereoselective in both the ECS and control animals (bottom of Fig. 3). Whereas $63 \%$ of the 


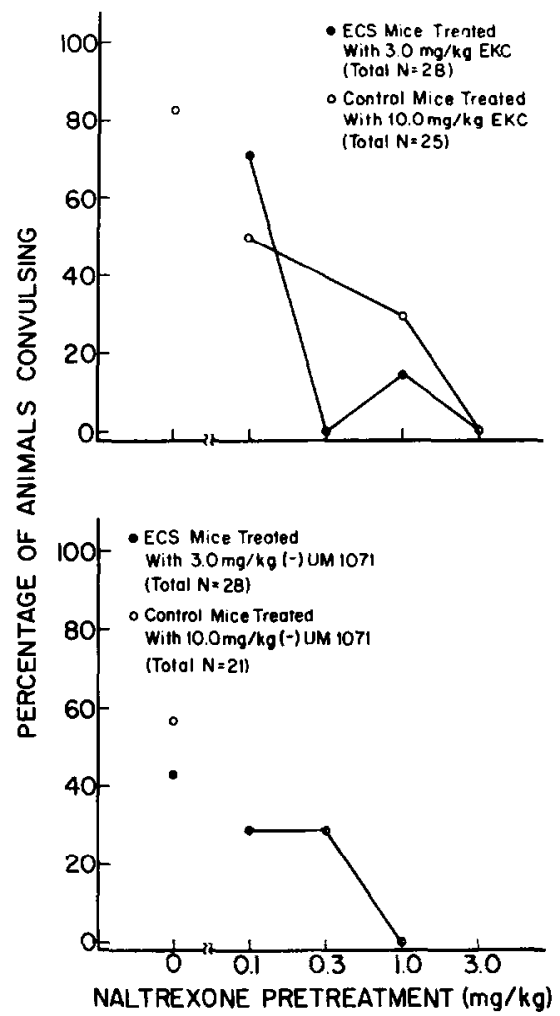

FIG. 4. Percentage of ECS and control mice convulsing to EKC or (-)UM 1071 administered 5 min after saline or different doses of naltrexone. All data points are based on six or more animals. All control animals were handled the same as ECS animals, but were not shocked. There was no difference between the two groups in the bottom figure; the data points overlapped.

ECS animals convulsed to $3 \mathrm{mg} / \mathrm{kg}(-) \mathrm{UM} 1071$, none of the animals convulsed at doses of either 10 or $100 \mathrm{mg} / \mathrm{kg}(+) \mathrm{UM} 1071$. A dose of 170 $\mathrm{mg} / \mathrm{kg}(+) \mathrm{UM} 1071$ was needed to induce convulsions in these animals. Similarly, whereas $71 \%$ of the control mice convulsed to $10 \mathrm{mg} / \mathrm{kg} \mathrm{(-)UM}$ 1071 , no control animal convulsed at a dose of $100 \mathrm{mg} / \mathrm{kg}(+) \mathrm{UM} 1071$, and only one of six convulsed at $170 \mathrm{mg} / \mathrm{kg}$. It required a dose of $300 \mathrm{mg} /$ $\mathrm{kg}(+) \mathrm{UM} 1071$ to reliably induce convulsions in control animals. It was apparent from these results that, in addition to being more sensitive to the levorotatory form of UM 1071, ECS animals were more sensitive to $(+) U M$ $1071(170 \mathrm{mg} / \mathrm{kg})$ compared with their controls $\left(\chi^{2}=10.37, P<0.01\right)$.

Experiment III. The changes that followed ECS, although not limited to opiates, were not observed with all nonopiate convulsant agents. Whereas 

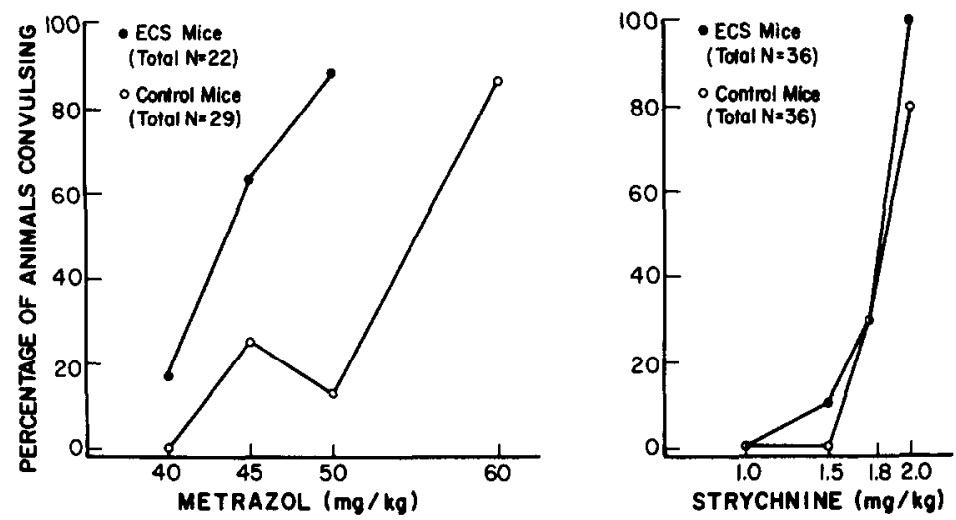

FIG. 5. Percentage of ECS and control mice convulsing to metrazol (left) or strychnine (right) 3 days after seven ECSs. All controls were handled the same as ECS animals, but were not shocked. All data points were based on six or more animals.

ECS animals were more sensitive to metrazol than control mice $\left(\chi^{2}=9.00, P<0.01\right.$ at $\left.50 \mathrm{mg} / \mathrm{kg}\right)$, they did not differ in their sensitivity to strychnine (Fig. 5).

Experiment $I V$. The changes in responsiveness to morphine and EKC. were found to vary with the number of convulsions, and the time between an animal's last convulsion and drug testing. Animals receiving 23 ECSs showed a full log unit shift to the left in their responsiveness to EKC (Fig. 6), compared with the only one-half $\log$ unit shift observed in animals receiving seven ECSs.

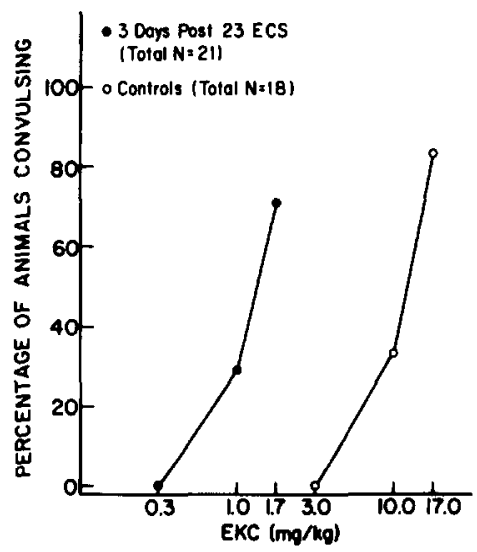

FIG. 6. Percentage of ECS mice convulsing to EKC 3 days after 23 ECSs. Control animals were handled the same as ECS animals, but were not shocked. All data points are based on six or more animals. 
Animals tested a month after their last of seven ECSs still showed changes in responsiveness to morphine. There was a small, but not significant ( $\chi$ $=0.71$, n.s.), decline in the effect with time, as $50 \%$ of the ECS mice tested at 30 days convulsed to morphine $(100 \mathrm{mg} / \mathrm{kg})$ compared with $71 \%$ that convulsed to this dose 7 days after their last ECS.

The induction of convulsions was necessary in producing these changes in opiate responsiveness, as repeated subconvulsive doses of EKC $(1 \mathrm{mg} /$ $\mathrm{kg}$ ) failed to produce a shift in morphine sensitivity. Convulsive doses of EKC $(10 \mathrm{mg} / \mathrm{kg})$ were, however, effective in producing changes in morphine responsiveness (Fig. 7). The magnitude of the changes observed with EKC $(10 \mathrm{mg} / \mathrm{kg}$ ) treatment was comparable to that seen following an equal number of electroconvulsive shocks.

\section{DISCUSSION}

The results demonstrate that mu and kappa agonists produce convulsions through different mechanisms in normal control animals. Mu agonists produce convulsions only at lethal doses, cannot be blocked by naltrexone, and their relative potencies are not consistent with established opiate receptor responses. Levorphanol is normally more potent than morphine, which in turn is more potent than codeine in producing known opiate receptor mediated responses, such as analgesia and locomotor changes (10, $12,15)$. We found, however, that codeine is most potent at producing convulsions in normal mice, followed by morphine, with levorphanol failing to elicit convulsions even at lethal doses. These results are consistent with

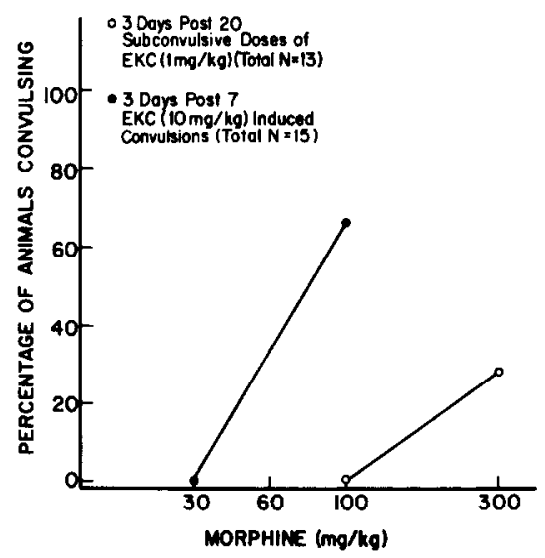

Fig. 7. Percentage of animals convulsing to morphine 3 days after a regimen of subconvulsive $(1 \mathrm{mg} / \mathrm{kg})$ or convulsive $(10 \mathrm{mg} / \mathrm{kg})$ doses of EKC. All data points are based on six or more animals. 
other reports demonstrating that codeine produces convulsions at smaller doses than morphine (1) and that pretreatment with opiate antagonists is unable to block morphine's convulsant effects $(5,16)$. In addition, Labella et al. (6) found that intraventicular injection of morphine produced seizures, but similar injections of levorphanol failed to do so even at large doses. Kappa agonists, on the other hand, produced convulsions that are not lethal, that can be blocked by naltrexone, and that are sensitive to the stereospecificity of the drug. Taken together, these results suggest that the convulsions observed with $\mathrm{mu}$ opiates are not mediated by an opiate receptor, whereas those induced by kappa agonists are a specific opiate receptor response.

After a series of convulsions, ECS animals show a marked qualitative change in their response to mu agonists. Although mu agonists produce convulsions by a nonopiate mechanism in normal mice, our evidence indicates that following ECS the convulsions induced by mu opiates are consistent with an opiate receptor response. In electroconvulsed animals, responses to mu agonists can be blocked by naltrexone pretreatment and show a pattern of drug effects that is consistent with other established opiate receptor-mediated responses. Levorphanol is more effective in inducing convulsions than morphine in the ECS animals, which in turn is more effective than codeine. The relative effectiveness of these mu agonists is the opposite of that observed in normal control animals. Further, the changes in responsiveness to opiates appear to be long-lasting and can be detected for as long as 1 month after an animal's last electroconvulsive shock.

It is unlikely that the change in responsiveness to mu opiates represents a simple change in sensitivity for, if that were the case, naltrexone should have been able to block the convulsions in both the ECS and normal mice, rather than blocking the response only in animals that received ECS; the relative effectiveness of mu agonists should have been the same in both the ECS and normal mice, and it was not; and levorphanol should have been able to produce convulsions in both the ECS and normal mice, and it did not. In contrast, the changes observed in response to kappa agonists did reflect a change in sensitivity. Kappa agonists produced nonlethal convulsions in both the ECS and normal mice; the convulsions were blocked by naltrexone in both ECS and normal mice; and the convulsions showed stereoselectivity in both the ECS and normal mice.

These changes in responsiveness to opiates may reflect changes in endogenous brain opioid systems. Consistent with this notion, Holaday et al. (4) reported that repeated ECS produced an increase in delta opioid receptor number without changing receptor affinity. Although an increased kappa receptor number or affinity might explain the enhanced sensitivity observed with kappa agonists, such an effect is unlikely to explain the 
changes observed with mu agonists, for ECS animals show a qualitatively different response to these drugs.

The induction of convulsions appears to be necessary in inducing these changes, as subconvulsive doses of EKC failed to produce a change in responsiveness to morphine. A change in morphine responsiveness was observed, however, when a convulsant dose of EKC was used. The EKCinduced convulsions produced a change in morphine responsiveness comparable to that seen following an equal number of electroconvulsive shocks. This result is consistent with our earlier findings (9) which indicated that the changes were not specific to the kind of convulsion induced and could be produced by repeated metrazol, ECS, or kindled convulsions. The magnitude of the changes does depend, to some extent, on the number of convulsions induced; we found that animals receiving 23 ECSs showed a more pronounced change in sensitivity to EKC than animals given only seven ECSs.

The changes in responsiveness to mu and kappa opiates cannot be explained exclusively on the basis of a general increase in seizure susceptibility. We found that whereas ECS animals are more sensitive to metrazol, they are not more sensitive to strychnine. Sangdee et al. (13) similarly reported that animals which have undergone ECS kindling were more sensitive to bicuculline and metrazol, but showed no change in their sensitivity to strychnine or picrotoxin.

It is also unlikely that the changes observed with mu agonists are due to damage of the blood-brain barrier. An increased permeability in the bloodbrain barrier is unlikely to explain the qualitative changes in responsiveness to mu opiates observed to follow ECS. Although changes in the permeability of the blood-brain barrier could have contributed to the increased sensitivity observed to kappa agonists, this does not seem highly likely as generalized damage of the blood-brain barrier might be expected to produce a global increased sensitivity to all convulsants, which was not found to be the case.

Whether repeated ECS renders subjects more seizure-prone is controversial. Although it is claimed that psychiatric patients do not become more seizureprone after a series of ECS (14), our research and that of others $(11,13)$ clearly indicates that animals may indeed be more seizure-prone, at least in response to certain drugs, after a series of convulsions.

\section{REFERENCES}

1. CORRADO, A. P., AND V. G. LONGO. 1961. An electrophysiological analysis of the convulsant action of morphine, codeine and thebaine. Arch. Int. Pharmacodyn. 132: 255-269.

2. CREESE, I., AND S. H. SNYDER. 1975. Receptor binding and pharmacological activity of opiates in the guinea-pig intestine. J. Pharmacol. Exp. Ther. 194: 205-219. 
3. Hein, D. W., A. W. Young, S. Herling, AND J. H. WoOds. 1981. Pharmacological analysis of the discriminative stimulus characteristics of ethylketazocine in the rhesus monkey. J. Pharmacol. Exp. Ther. 218: 7-15.

4. Holaday, J. W., R. J. HitzemanN, J. Curell, F. C. Tortella, and G. L. Belenky. 1982. Repeated electroconvulsive shock or chronic morphine treatment increases the number of H-D-ALA, D-Leu-enkephalin binding sites in rat brain membranes. Life Sci. 31: 2359-2362.

5. Koppanyi, T., AND A. G. KarCZMar. 1953. Nature of antagonism between N-allylnormorphine (Nalline) and morphine. Fed. Proc. 12: 337.

6. Labella, F. S., C. PINSKY, AND V. HAVLICEK. 1979. Morphine derivatives with diminished opiate receptor potency show enhanced central excitatory activity. Brain Res. 174: 263271.

7. Magnan, J., S. J. Paterson, A. Tavani, and H. W. Kosterlitz. 1982. The binding spectrum of narcotic analgesic drugs with different agonist and antagonist properties. Nauyn-Schmiedeberg's Arch. Pharmacol. 319: 197-205.

8. Mansour, A., R. DOYLe, R. KaTZ, and E. S. VALENSTEIN. 1981. Long-lasting changes in morphine sensitivity following amygdaloid kindling in mice. Physiol. Behav. 27: 1117-1120.

9. Mansour, A., AND E. S. VAlENSTEIN. 1984. Morphine sensitivity and seizure proneness. Exp. Neurol. 85: 346-357.

10. PerT, C. B., AND S. H. SNYDER. 1973. Properties of opiate-receptor binding in rat brain. Proc. Natl. Acad. Sci. U.S.A. 70: 2243-2247.

11. Ramer, D., AND J. P. J. Pinel. 1977. Progressive intensification of motor seizures produced by periodic electroconvulsive shock. Fxp. Neurol. 51: 421-433.

12. RETHY, C. R., C. B. SMITH, AND J. E. VILLARREAL. 1971. Effects of narcotic analgesics upon the locomotor activity and brain catecholamine content of the mouse. J. Pharmacol. Exp. Ther. 176: 472-479.

13. SANGdee, P., S. A. TURKanis, AND R. Karler. 1982. Kindling-like effect induced by repeated corneal electroshock in mice. Epilepsia 23: 471-479.

14. Small, J. G., V. Milstein, I. F. Small, AND P. H. Sharpley. 1981. Does ECT produce kindling? Biol. Psychiat. 16: 773-778.

15. Terenius, L. 1974. Contribution of "receptor" affinity to analgesic potency. Comm. J. Pharm. Pharmacol. 26: 146-148.

16. WINTER, C. A., AND L. FLATAKER. 1956. Effect of $N$-allylnormorphine upon massive doses of narcotic drugs. Proc. Soc. Exp. Biol. Med. 93: 158-160.

17. Woods, J. H., C. B. Smith, F. Medzihradsky, and H. H. Swain. 1979. Preclinical testing of new analgesic drugs. Pages $429-445$ in R. F. BeERS JR. AND E. G. BASSETt, Eds., Mechanism of Pain and Analgesic Compounds. Raven Press, New York. 